luna Hernández, María Helena, “Marginalidad en el Código penal colombiano. Contexto de análisis y reflexiones de pandemia", Nuevo Foro Penal 97, (2021).

\title{
Marginalidad en el Código Penal colombiano. Contexto de análisis y reflexiones de pandemia.
}

Marginalization in the Colombian Criminal Law. Analysis and thoughts about pandemic context.

María Helena Luna Hernández

Fecha de recepción: 30/06/2021. Fecha de aceptación: 23/09/2021

DOI: $10.17230 / n f p 17.97 .4$

\section{Resumen}

En el presente artículo se proporcionarán datos de la realidad social colombiana, con los cuales se pretende introducir el desarrollo penal de las circunstancias de atenuación punitiva consagradas en el artículo 56 del Código Penal colombiano, cuyo

1 Abogada de la Universidad de Medellín, magíster y especialista en Derecho Penal de la Universidad Eafit, Antioquia. Con estudios de maestría en Derecho Penal y Política Criminal de la Universidad de Málaga, España. Juez Penal del Circuito de La Ceja-Antioquia. Docente de posgrado en las universidades del Rosario (Bogotá), Los Andes (Bogotá), U. Católica (Bogotá), U. Nariño y U. de Manizales. Docente del Centro de Estudios Socio Jurídicos Latinoamericanos, CESJUL, capacitadora en la Corporación Anne Frank, en el proyecto de formación en DD.HH. y DIH 'Cuidar Vidas', para hombres y mujeres de protección. Conferencista nacional e internacional en temas de derecho procesal penal, política criminal y género. Columnista especializada en temas jurídicos en el periódico Ámbito Jurídico, la Revista Derecho, Debates \& Personas y la emisora URosario Radio. Correo electrónico helena_hernandez77@hotmail.com 
denominador común subyace en el fenómeno de la marginalidad, siendo éste sobre el que se profundizará. A partir de algunos planteamientos de juristas latinoamericanos, se justificará la necesidad de desarrollar criterios de corresponsabilidad penal, que encuentren un anclaje entre la dogmática penal y el contexto de su aplicación.

\section{Abstract}

This article will provide data on the Colombian social reality, with which it is intended to introduce the criminal development of the circumstances of punitive mitigation enshrined in article 56 of the Colombian Penal Code, whose common denominator lies in the phenomenon of marginalization, being this the phenomenon on which it will be deepened. Based on some proposals from Latin American jurists the need to develop criteria of criminal co-responsibility, that find an anchor between criminal dogmatics and the context of its application will be justified.

\section{Palabras clave}

Corresponsabilidad penal, Estado social de derecho, culpabilidad, derecho penal, vulnerabilidad, selectividad, autodeterminación, legitimidad.

\section{Keywords}

Criminal responsibility, Social State of Law, culpability, criminal law, vulnerability, selectivity, self-determination, legitimacy.

\section{Sumario}

1. Introducción. 2. Mapeo de la marginalidad colombiana. 3. La marginalidad en

el Código Penal colombiano. 4. La responsabilidad del hombre como actor social.

5. Culpabilidad por vulnerabilidad. 6. El sujeto social como punto de encuentro 7. Conclusiones. Bibliografía.

\section{Introducción.}

Colombia es un país donde las condiciones de pobreza y exclusión de gran parte de la población aumentan sus probabilidades de selección por cuenta del sistema penal, así como la persecución y juzgamiento de ciertas formas de criminalidad. En este contexto es relevante determinar, a partir de la dogmática penal, cuándo es posible incluir como eximente de responsabilidad penal la circunstancia de marginalidad consagrada en el artículo 56 del Código Penal Colombiano.

Para lograr tal propósito, en un primer apartado se dará cuenta de las cifras 
y mediciones sobre situaciones de pobreza y exclusión en el contexto colombiano, integrando dicha estadística en los supuestos de la marginalidad como fenómeno social y derivando una definición estipulativa sobre este concepto.

Posteriormente se abordará la recepción de la circunstancia de marginalidad en el Código Penal colombiano, y se expondrán razones para propugnar la exclusión 0 atenuación de la culpabilidad en circunstancias de marginalidad, para lo cual se aprehenderán los presupuestos de corresponsabilidad penal derivados de la teoría del sujeto responsable ${ }^{2}$, así como la denominada culpabilidad por vulnerabilidad ${ }^{3}$.

Si bien este artículo no tiene como propósito desarrollar los criterios de aplicación de la corresponsabilidad penal (responsabilidad penal compartida, concebida como el aporte conjunto de la sociedad, el Estado y el individuo en la comisión delictiva 0 en sus causas generadoras), sí brindará los insumos para justificar y materializar un análisis de dicha corresponsabilidad al interior de la categoría dogmática de la culpabilidad, específicamente en su componente de exigibilidad.

Abordar la temática propuesta responde a la necesidad de colmar la carencia de desarrollo dogmático sobre la circunstancia de marginalidad extrema y su tratamiento jurídico penal en el contexto colombiano, teniendo en cuenta que no existe delimitación de su ámbito de configuración en la jurisprudencia nacional, esto es, la posibilidad de eximir la responsabilidad penal cuando se pruebe el condicionamiento delictivo derivado de la circunstancia objeto de estudio. Todo ello adquiere relevancia social, así como implicaciones prácticas respecto de la punibilidad y los criterios graduales de la misma, al constatarse determinados supuestos fácticos.

\section{Mapeo de la marginalidad colombiana.}

Breve contexto internacional.

La desigualdad social y económica en Colombia y el mundo se ha agudizado con la pandemia. De acuerdo con el más reciente informe del Índice de Desarrollo Regional para Latinoamérica ${ }^{4}$, Colombia, a diciembre de 2020, es el país más desigual de toda la región.

2 Bustos Ramírez, Juan José y Hormazábal, H. Lecciones de Derecho penal, Volumen II. Madrid: Trotta, 1999, pp. 311-337.

3 Zaffaroni, Eugenio R y Alagia, Alejandro y Slokar, Alejandro. Derecho Penal Parte General. Segunda Parte. Segunda edición. Buenos Aires, Argentina: Ediar Sociedad anónima editora, comercial, industrial y financiera, 1998, pp. 648- 683 
En el más reciente informe sobre la desigualdad, $0 \mathrm{xfam}^{5}$ revela datos alarmantes, y aún más en temas de equidad de género, pues tan sólo 22 hombres del globo terráqueo concentran la riqueza que, en la misma cantidad, deben compartir todas las mujeres de África. Lo que es más, tan solo el 1\% de la población mundial (el más rico del globo) concentra más del doble de riqueza que 6.900 millones de personas.

Bajo el título Cinco datos escandalosos sobre la desigualdad extrema global y cómo combatirla, Oxfam ha presentado los más recientes datos de desigualdad en el mundo, prendiendo aún más las alarmas, pues el escenario paralelo a la pandemia es desalentador. Precisa que nunca antes hubo tantos millonarios cuya riqueza crece sin tregua, equivaliendo a una cifra superior de lo que posee el $60 \%$ de la población mundial (4600 millones de personas), misma suerte que corre la extrema pobreza alrededor del mundo, padecida por más de 735 millones de seres humanos. Si bien sostiene la entidad que basta una mala cosecha o una factura médica para sumarse a las estadísticas de pobreza extrema; es preciso decir que bastó un virus para desdibujar la delgada y frágil línea entre pobreza y el extremo de esta. Los pobres, tras la aparición del Covid-19, son mucho más pobres.

Se estima que alrededor de la mitad de la población mundial debe sobrevivir con 5.50 dólares al día. Por otro lado, desalentador resulta que los más ricos, al acceder a asesorías profesionales de alto nivel y a una mayor influencia en la clase política, logran eludir hasta el $30 \%$ de sus responsabilidades tributarias. La brecha impositiva es tal, que de acuerdo con la entidad, solo 4 centavos de cada dólar recaudado por el fisco mundial proceden de gravámenes a la riqueza.

Así mismo, dirige la atención a la desigualdad en temas de género, explica que son mujeres y niñas las más afectadas con todas estas coyunturas económicas, muy a pesar de su importante rol no remunerado en el hogar. Lo más traumático radica en la abismal diferencia en el acceso a la educación, puesto que frente a 100 niños infortunadamente desescolarizados, corren la misma suerte 121 niñas. La realidad distributiva nacional adolece de los mismos males, de acuerdo con Idere Latam ${ }^{6}$, somos el segundo país más desigual para las mujeres de la región, solo superados por Argentina.

Es categórico pensar que la riqueza equivale a la sumatoria de talento, esfuerzo

http://www.iderelatam.com Mayo 26 de 2021.

5 Oxfam International. "Cinco datos escandalosos sobre la desigualdad extrema global y cómo combatirla" Recuperado de: https://www.oxfam.org/es/cinco-datos-escandalosos-sobre-ladesigualdad-extrema-global-y-como-combatirla, consultado en mayo 26 de 2021.

6 Resultados del Índice de Desarrollo Regional - Latinoamérica (IDERE LATAM). Recuperado de: http://www.iderelatam.com/, cit. 
e innovación, pero no debe perderse de vista que otras fuentes contribuyen al acaparamiento de la riqueza, como lo son la corrupción y los capitales heredados, con sus consecuentes efectos adversos, como los monopolios, y la elevada elusión fiscal, por mencionar un par de ejemplos.

Aunado a lo anterior, la pandemia ha favorecido un escenario donde los ricos son cada vez más ricos, y la pobreza extrema es cada vez más profunda, situación de penuria que tiene una relación casi directamente proporcional con la desigualdad entre sexos, lo que indica que una reducción de la segunda, menguará la primera.

La nueva fuerza laboral, jóvenes sin suficiente preparación y oportunidades, no es más que la renovada dinámica de dependencia, así como el trabajo para salir de la pobreza no es más que un eufemismo, pues tal como estima la Organización Mundial del Trabajo (OIT), cada vez es menos cierto escapar de la pobreza al obtener un empleo. Aproximadamente una de cada tres personas con trabajo en países emergentes o en desarrollo vive en la pobreza, proporción que va en aumento ${ }^{7}$ y que tras la llegada de la pandemia ${ }^{8}$, se ha agudizado, restando aún más las condiciones dignas a quienes realmente producen los beneficios económicos, pues los salarios no reflejan el crecimiento de las economías, muy por el contrario, la mano de obra se encuentra mal remunerada, la mujer se encuentra relegada sin pago alguno, y la industria mundial ha manifestado una tendencia a maximizar sus utilidades en lugar de promover una redistribución de la riqueza que permita mayores beneficios económicos y sociales.

Colombia, un país de vergonzosa desigualdad.

Distribución de tierras.

Colombia, un país biodiverso, encumbrado en fuentes hídricas y atravesado por tres cordilleras, se caracteriza por su aptitud agrícola, dada la extensión y calidad de sus tierras, así como su clima tropical. De ahí que hablar de desigualdad en Colombia es, en definitiva, hablar de distribución inequitativa de tierras.

De hecho, la desigualdad socioeconómica del país es, a la vez, causa y efecto

7 Oxfam Internacional, "Premiar el trabajo, no la riqueza", 2018. Recuperado de: https:// d1tn3vj7xz9fdh.cloudfront.net/s3fs-public/file _ attachments/bp-reward-work-not-wealth-220118es.pdf. Consultado en mayo 26 de 2021.

8 Oxfam Internacional, “Poder, ganancias y pandemia. De una economía para las élites a una economía para las personas", 2020. Recuperado de: https://www.oxfam.org/es/informes/poder-ganancias-ypandemia. Consultado en mayo 26 de 2021. 
del conflicto armado en Colombia, que de antemano se advierte: representa una clara muestra del incumplimiento estatal de sus deberes para la prevención del conflicto 9 . Por ello, el acuerdo de paz con las FARC-EP ha sido de relevancia nacional e internacional, y tiene como principal motor, la reforma rural 0 agraria ${ }^{10}$, con énfasis en la distribución de tierras.

Ahora, al margen de la poca credibilidad de la que gozan las instituciones oficiales ${ }^{11}$, especialmente el Departamento Nacional de Estadísticas (DANE), es necesario recurrir a sus datos, pues son la única fuente de información directamente disponible, y es de sus estadísticas que se obtuvo como muestra una alarmante concentración productiva rural en los grandes poseedores de tierras, agudizada bajo la omisión de censos rurales y la precaria actualización catastral.

Se presenta un gráfico al respecto:

\section{EVOLUCIÓN DEL ÍNDICE DE GINI EN LA DISTRIBUCIÓN DE LA PROPIEDAD RURAL (1960 A 2014)}

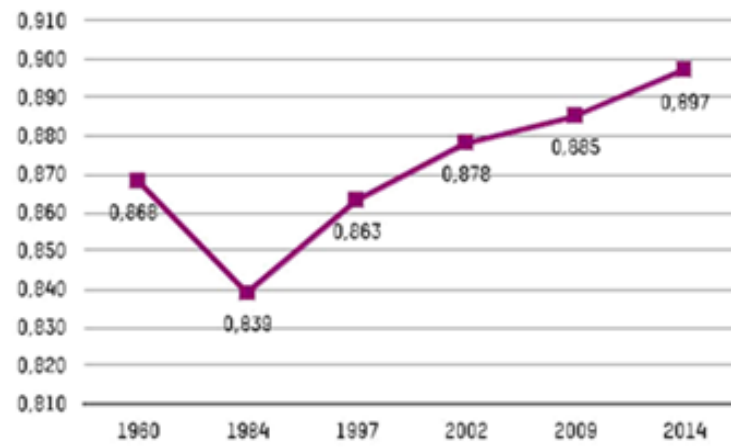

Fuente: Instituto Geográfico Agustín Codazzi (2012)

GRÁFICO 1 *Infortunadamente, hace casi una década no se actualizan las cifras.

9 Corte Constitucional de Colombia, Sentencia C-179 de 1994, M.P. Carlos Gaviria Díaz. La providencia refiere los derechos de prevención y resolución de conflictos internos por parte del Estado.

10 Acuerdo Final para la Terminación del Conflicto y la Construcción de una Paz Estable y Duradera, Colombia, 2016. Recuperado de:

http://www.altocomisionadoparalapaz.gov.co/procesos-y-conversaciones/Paginas/Textocompleto-del-Acuerdo-Final-para-la-Terminacion-del-conflicto.aspx

11 En Colombia la desinformación es rey. "El problema es que la información en Colombia es sumamente parcial, discontinua y dispersa." Oxfam Internacional, 2017. "Radiografía de la desigualdad". Recuperado de: https://d1tn3vj7xz9fdh.cloudfront.net/s3fs-public/file _ attachments/radiografia _ de la _ desigualdad.pdf. Consultado en mayo 26 de 2021.

Con ocasión de los tratados de paz, los censos rurales debieron ser actualizados a última hora y con grandes esfuerzos, que reflejaron falta de técnica y logística. 
Como se puede observar, a partir de 1984 la desigualdad en la distribución de la propiedad rural en Colombia ha ido creciendo sistemáticamente. Ahora, el DANE emplea el término UPA para referirse a las Unidades de Producción o explotación agropecuaria, entendidas como aquel fragmento de tierra con una única o múltiple circunscripción administrativa que comparte los medios de producción. Luego de esta precisión, en el siguiente gráfico se puede ver la evolución de la superficie en esta unidad:

EVOLUCIÓN DE LA SUPERFICIE EN UPAs DE MÁS DE 500 HECTÁREAS IEN ROJO)

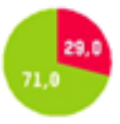

1960

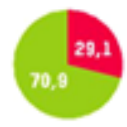

1970

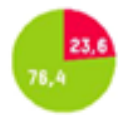

1984

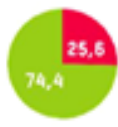

1997

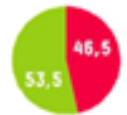

2002

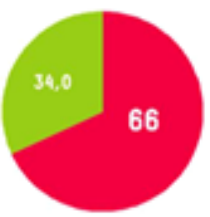

2014

Fuente: Oxfam, 2017. GRÁFICO 2

Puede concluirse, sin mayores tecnicismos, que mientras los grandes territorios en manos de unos pocos aumentaban en cantidad y en producción, las pequeñas unidades productivas iban en declive. Para ahondar un poco más, véase:

\section{EVOLUCIÓN DEL TAMAÑO PROMEDIO DE LAS UPAS DE MÁS DE 500 HECTÁREAS}

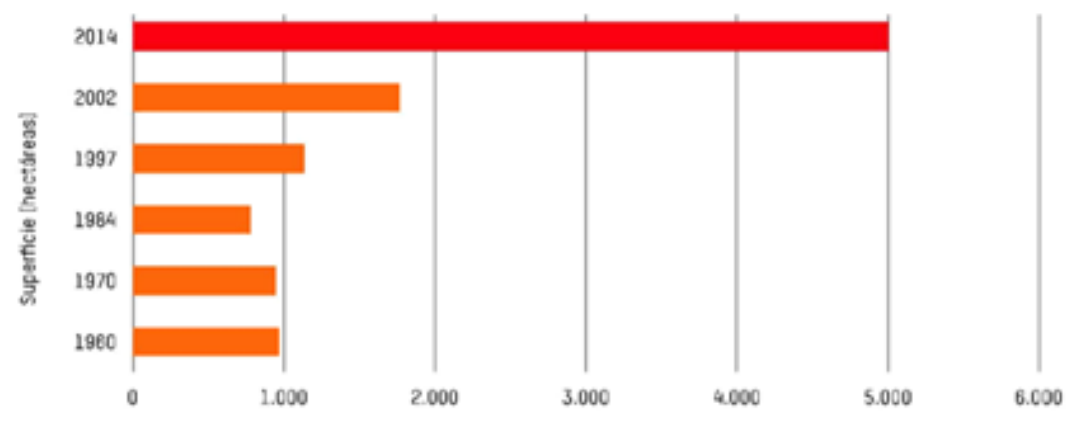

Fuente: Oxfam, 2017. GRÁFICO 3

Igualmente, del gráfico anterior se desprende que Colombia tiene una alta propensión a concentrar grandes tierras. A partir de aquí las siguientes cuestiones que hay que suscitar son las de quienes las explotan y qué porcentaje representan de la superficie total. 


\section{PORCENTAJE DE TIERRA OUE MANEJA EL $1 \%$ DE LAS EXPLOTACIONES MÁS GRANDES}

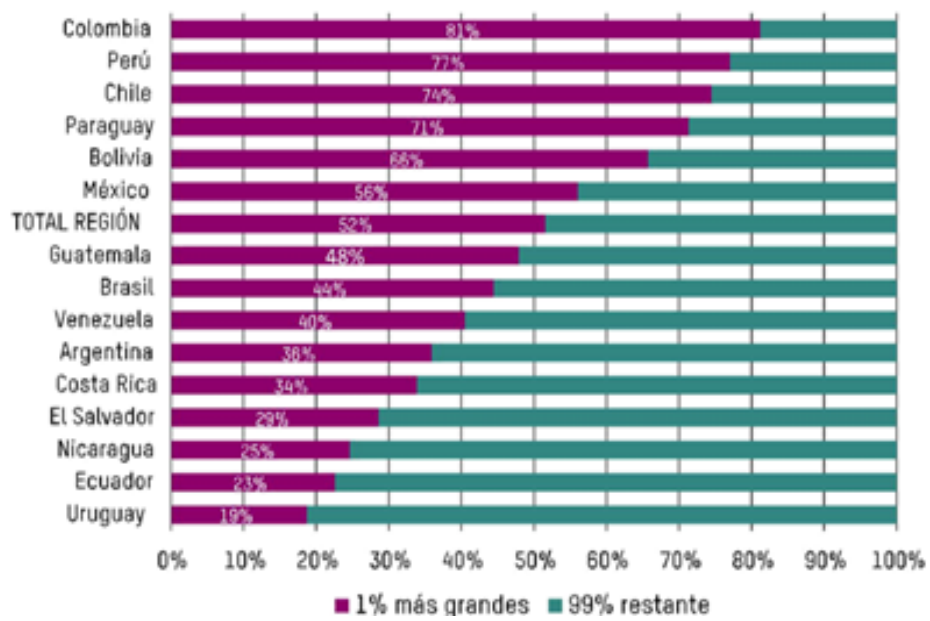

Fuente: Oxfam, 2017. GRÁFICO 4

Como se puede ver, Colombia es el país donde el $1 \%$ de los titulares de las grandes explotaciones agrícolas concentra el mayor porcentaje de la superficie agrícola total de toda Latinoamérica.

También es controversial que quienes ostentan más del $50 \%$ de las tierras en producción, son personas jurídicas, es decir, empresas, y no así campesinos. Si dicha cifra fuese por procesos de tecnificación de los campesinos o de formalización y estuviera lo suficientemente documentado, no habría lugar a la especulación, pero lo cierto es que Colombia viene de un proceso de violencia y desplazamiento forzado en las zonas rurales, por lo que gran parte de estas empresas son fachadas ilegales. "También destaca el hecho de que dos tercios de la superficie productiva está manejada por personas jurídicas, las cuales residen, mayoritariamente, fuera del área rural."12

Con relación al uso del suelo, resulta sencillo advertir la alta demanda de alimentos importados ${ }^{13}$, no obstante ser un territorio supremamente fértil y vasto

12 Oxfam Internacional, "Radiografía de la desigualdad". P.18, 2017. Recuperado de: https:// d1tn3vj7xz9fdh.cloudfront.net/s3fs-public/file _ attachments/radiografia _ de _la _ desigualdad. pdf. Consultado en mayo 26 de 2021.

13 Acción social Colombia y Unión Europea (2011). Campesinos, tierra y desarrollo rural. Recuperado de: http://eeas.europa.eu/archives/delegations/colombia/documents/projects/cartilla _ tierra _ Y desarrollo_lab_paz_iii_es.pdf 
como para cubrir sus necesidades básicas ${ }^{14}$ alimentarias sin tener que cruzar fronteras. Un punto clave sobre el tema es el problema de la titularidad de la tierra en Colombia, donde, gracias a la altísima corrupción, la violencia y sus desplazamientos forzados, la desidia administrativa por invertir en un catastro funcional para el país y los intereses de unos pocos, se ha permitido que los suelos que eran empleados por los agricultores para cultivar alimentos -pues esa es la naturaleza y predisposición de dichos terrenos- sean usados por los grandes ganaderos.

“En todo el país se calcula que existen 15 millones de hectáreas con aptitud para ganadería, pero se utilizan para este uso más del doble: 34,4 millones de hectáreas. Por el contrario, existe una subutilización del área potencialmente aprovechable para el establecimiento de cultivos, ya que solo se emplean para este fin 8, 5 millones de hectáreas, menos del 40\% de los 22 millones con aptitud agrícola."15

\section{USO DEL SUELO (MILLONES DE HECTÁREAS)}

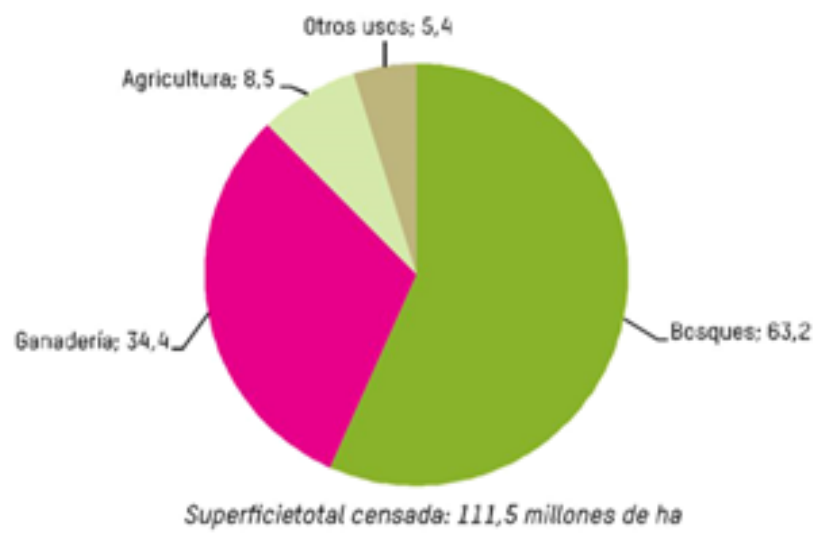

Fuente: DANE, 2016.GRÁFICO 5

\section{Pobreza multidimensional.}

Según el reporte oficial del Programa de Desarrollo Humano de las Naciones Unidas, las cifras de pobreza multidimensional complementan los datos netamente de ingresos monetarios al respecto, pues éstas consideran las privaciones superpuestas

14 Organización de las Naciones Unidas (2011). Colombia rural, razones para la esperanza. Recuperado de: https://www.undp.org/content/dam/colombia/docs/DesarrolloHumano/undp-co-ic _ indh2011parte1-2011.pdf

15 Oxfam Internacional, "Radiografía de la desigualdad", cit., p.23, 2017. 
que sufren los individuos en un mismo momento, tales como necesidades a nivel del hogar, salud, educación y calidad de vida. De igual manera, el índice de pobreza multidimensional identifica privaciones en las mismas tres dimensiones que el Índice de Desarrollo Humano (IDH) y, a más de ello, muestra el número de personas que son multidimensionalmente pobres (que sufren privaciones en el $33 \%$ o más de los indicadores ponderados), así como la prevalencia de sus carencias multidimensionales y su intensidad, es decir, cuántas carencias, discriminadas de manera multidimensional, sufren las personas a la vez y qué relevancia tienen de manera individual y agregada.

De acuerdo con los últimos datos de Naciones Unidas, Colombia tiene una población en condición de pobreza multidimensional del 17.5\%, y va en aumento. La crisis sanitaria ha desembocado en hechos históricos desde el colapso económico de 1929, y, comprendiendo a Colombia, la CEPAL para finales del 2020 pronosticó un "impacto no sólo en la generación económica de los países, sino también una profundización importante en los niveles de desigualdad y pobreza. Al finalizar el 2020, la pobreza alcanzará un 34.7\% y la pobreza extrema un 13.5\% en la región. Es decir, más de 28 millones de personas entrarían en situación de pobreza (...)."16

El Índice de Compromiso con la Reducción de la Desigualdad (CRI) 2020 (OXFAM) ${ }^{17}$, proyecta condiciones opacas para la humanidad en general y para los países en desarrollo en particular. Tras la pandemia se hizo más evidente que tan solo uno de cada seis países realiza inversiones adecuadas en salud; solo una tercera parte de la población laboral activa es cubierta por protección social; y uno de cada tres trabajadores carece de herramientas tan necesarias para paliar coyunturas económicas, como lo es una licencia remunerada por enfermedad o convalecencia.

Los anteriores indicadores tienen algunas variaciones desfavorables al contrastarse con la información del DANE para los datos obtenidos en el 2016. El reporte de la población en pobreza multidimensional en Colombia representa el $17,8 \%$, lo que es igual a 8'586.000 personas (Departamento Administrativo Nacional de Estadística, 2017).

En 2016 el 28,0\% de los colombianos estaba en condición de pobreza

16 Fernández de Soto, Guillermo. "Colombia y el 75 aniversario de las Naciones Unidas". Recuperado de https://www.un.org/pga/74/wp-content/uploads/sites/99/2020/06/Texto-Colombia-y-ONU-75an\%CC\%83os-junio-18-2020-final.pdf. Consultado en mayo 26 de 2021.

17 Oxfam Internacional. “Combatir la desigualdad en tiempos de coronavirus: Índice de Compromiso con la Reducción de la Desigualdad (CRI) 2020". Recuperado de: https://www.oxfam.org/es/informes/ combatir-la-desigualdad-en-tiempos-de-coronavirus-indice-de-compromiso-con-la-reduccion-de. Consultado en mayo 26 de 2021. 
monetaria $^{18}$, en las cabeceras municipales fue de $24,9 \%$ y en los centros poblados y zonas rurales dispersas fue 38,6\%. Además, 8,5\% del total de la población estaba en condición de pobreza extrema. Finalmente, la valoración de distribución del ingreso en el 2016 medida a través del coeficiente de Gini fue de 0.517, lo que indica una desviación considerable de la distribución del ingreso entre individuos u hogares al alejarse del valor de 0 (representa igualdad absoluta).

Ahora bien, como se reseñó, el Idere ${ }^{19}$ ubicó recientemente a Colombia como el país más desigual de la región, siendo las dimensiones más afectadas las de bienestar socioeconómico, seguridad e instituciones por departamentos. Por su parte el FMI, si bien ha venido morigerando sus perspectivas de crecimiento económico en la región, prevé un alto incremento de informalidad laboral ocasionado por la crisis sanitaria, una pérdida de las ganancias sociales obtenidas hasta la fecha por países en desarrollo y el exacerbamiento de las brechas económicas.

Bajo el panorama bosquejado, resulta claro que existe un segmento de la población colombiana que vive en condiciones materiales de marginalidad, por cuanto sus dimensiones culturales, educativas, económicas y habitacionales están por debajo de los estándares mínimos de la línea de pobreza nacional e internacional. Los indicadores obtenidos en estas mediciones multidimensionales sirven para aproximar la realidad de una población y sus especificidades, sin que pudieran abordarse en su totalidad mediante estos procesos de cálculo. Un ejemplo de esto es la ausencia de datos sobre la afectación en el ámbito psicológico o de salud mental de la población en situación de pobreza multidimensional extrema.

Los grupos poblacionales en condiciones de marginalidad se caracterizan por su escasa infraestructura urbana, así como las dificultades de acceso a servicios públicos y recursos que faciliten sus estándares de calidad de vida. A ello hay que sumar los factores de desempleo o empleo informal, analfabetismo y disfuncionalidad familiar. Todo ello genera consecuencias en la formación psicosocial, autoestima, habilidades cognitivas, formación de la propia identidad y proceso de maduración emocional.

18 "(...) La ciudad con menor porcentaje de pobreza monetaria en 2016 fue Bucaramanga A.M. con 10,6\%, seguida por Bogotá D.C. con 11,6\% y Medellín A.M. con 14,1\%. La ciudad con mayor incidencia de pobreza monetaria en 2016 fue Quibdó con 49,2\%, seguida por Riohacha con 45,5\% y Valledupar con $35,5 \%$. La ciudad con menor porcentaje de pobreza monetaria extrema en 2016 fue Bucaramanga A.M. con $1,2 \%$, seguida por Pereira A.M. con $1,8 \%$ y Bogotá D.C. con 2,3\%. La ciudad con mayor incidencia de pobreza monetaria extrema en 2016 fue Quibdó con 19,5\%, seguida por Riohacha con $15,3 \%$ y Valledupar con 8,7\% (...)" (Departamento Administrativo Nacional de Estadística, 2017). 
Estos componentes han sido recogidos y analizados en trabajos guiados por la denominada teoría de la autodeterminación, que estudian la motivación intrínseca del sujeto y su autorregulación, concerniente a cómo las personas asumen los valores sociales y las contingencias extrínsecas, y transforman progresivamente estos en valores personales y auto-motivaciones ${ }^{20}$.

Siguiendo este planteamiento, las condiciones del contexto social de cada individuo influyen directamente en su desarrollo psicológico y los procesos de automotivación y autonomía. "La investigación también reveló que no solo las recompensas tangibles, sino que también las amenazas, las fechas de cumplimiento, las directivas, las presiones de las evaluaciones, y las metas impuestas reducen la motivación intrínseca debido a que, al igual que las recompensas tangibles, todas ellas conducen a un locus de causalidad percibida externo. En contraste, el sentido de elección, el reconocimiento de los sentimientos, y las oportunidades para una autodirección se hallaron que ampliaban la motivación intrínseca debido a que ellas permitín un mayor sentimiento de autonomía" ${ }^{21}$.La internalización y la integración son aspectos centrales de la socialización en la infancia, pero ellos también son continuamente relevantes para la regulación de la conducta en el curso de toda la vida.

A modo estipulativo, la marginalidad podría entenderse como un fenómeno social estructural, derivado de la inequidad de oportunidades y acceso a los procesos de desarrollo, que a su vez genera un déficit de satisfacción en las necesidades materiales básicas en quienes padecen tal realidad, generalmente ubicada en la periferia de las urbes 0 en zonas desarraigadas por circunstancias de violencia, desigualdades o pobreza. Dicha situación, contrario a un mal tiempo pasajero, requiere esfuerzos gigantescos para superarla, muchas veces insuficientes ante la ausencia de ayudas integrales y externas que permitan materializar un plan de vida digno conforme al programa constitucional suscrito.

Lo anterior para aproximar el contexto subyacente entre la marginalidad (con todos los factores que entraña) y la autodeterminación de un sujeto, supuestos necesariamente considerados al momento de determinar la culpabilidad y/o responsabilidad penal de un individuo, que también deberían ser imprescindibles en la forma de pensar el sistema penal colombiano, la optimización de mecanismos de terminación anticipada del proceso penal, así como de alternativas diferentes a las sancionatorias.

20 Ryan, Richard M. y Decl, Edward L. “La Teoría de la Autodeterminación y la Facilitación de la Motivación Intrínseca, el Desarrollo Social, y el Bienestar". En: American Psychologist, Vol. 75, 2000, pp. 1-3.

21 Ibíd., p. 4. 
Finalmente, para este apartado, se hace hincapié en lo sostenido por la ONU en su reciente informe ${ }^{22}$, donde el organismo multilateral refiere que la situación socioeconómica actual tiene dimensiones épicas y quedará como dato histórico para la posteridad. Afirma que no existe solución alguna que difiera de la tendencia que deben adoptar los países de cerrar las desigualdades socioeconómicas en sus territorios. Si bien la voluntad política se erige como el elemento inamovible en la agenda de cada Estado por salir adelante ante la crisis sanitaria imperante, los demás actores dialogan e impulsan la política, y ninguna arista profesional (menos el derecho penal), escapa a la responsabilidad por el encuentro de soluciones sostenibles ante la crisis.

\section{La marginalidad en el Código Penal colombiano.}

\section{Condición de Marginalidad.}

Pese a que desde la ley 599 del 2000, con la expedición del nuevo estatuto penal, se previó esta circunstancia ${ }^{23}$, su embrionario desarrollo teórico y jurisprudencial, limitaron su ámbito de aplicación a figuras de terminación anticipada del proceso penal como los preacuerdos ${ }^{24}$, y más allá de las discusiones sobre la proporción de su rebaja y las previsiones procedimentales de su aplicación, poco se ha desarrollado sobre el contenido o elementos configurativos de dicha circunstancia, bajo los cuales se pudiera racionalizar la aplicación del derecho penal, y restar la selectividad del poder punitivo.

Lo anterior se sustenta en el rastreo de jurisprudencia sobre las decisiones de la Corte Suprema de Justicia y la Corte Constitucional respecto de esta circunstancia

22 Asamblea General De las Naciones Unidas. "La extrema pobreza y los derechos humanos". Recuperado de: https://www.undocs.org/es/A/75/181/REV.1. Consultado en mayo 26 de 2021.

23 Artículo 56 del Código Penal colombiano: El que realice la conducta punible bajo la influencia de profundas situaciones de marginalidad, ignorancia o pobreza extremas, en cuanto hayan influido directamente en la ejecución de la conducta punible y no tengan la entidad suficiente para excluir la responsabilidad, incurrirá en pena no mayor de la mitad del máximo, ni menor de la sexta parte del mínimo de la señalada en la respectiva disposición.

24 Cuya aplicación acrítica y desproporción de rebajas, generó pronunciamos jurisprudenciales que restringieron y exigieron mayor rigor en su aplicación. Un ejemplo de esto es la sentencia SU 479/2019 de la Corte Constitucional. 
de atenuación punitiva. Solo en 4 sentencias ${ }^{25}$ y en 14 autos $^{26}$ de la Corte Suprema de Justicia se aborda el tema sin mucha novedad y desarrollo sobre la figura.

En todo caso, es uniforme la jurisprudencia de la Sala Penal de la Corte Suprema de Justicia, al considerar el artículo 56 del CP como circunstancia atenuante de la responsabilidad penal y no como eximente. En su última decisión ${ }^{27}$ sobre el tema, señala:

"(iv) Aunque profundas y extremas [las circunstancias delartículo 56 CP], esnecesario que no sean capaces de configurar una causal de exclusión de la responsabilidad, como podría ocurrir con la ignorancia que da cabida a un error de prohibición directo, o la pobreza capaz de configurar un estado de necesidad disculpante."

\section{La responsabilidad del hombre como actor social.}

Tomando los planteamientos de Bustos Ramírez, la responsabilidad del sujeto está adherida a la exigibilidad del Estado sobre cada individuo en relación con su conducta, exigencia que le es facultada en la medida que otorgue las condiciones para que dicha demanda de comportamiento conforme a derecho sea posible. Es una imputación social realizada al individuo, que requerirá auscultar las circunstancias que rodearon al mismo en cada caso concreto.

Para Bustos y Hormazába ${ }^{28}$ el elemento de la exigibilidad constituye fundamento del juicio de responsabilidad individual. Habrá que determinarse a partir de qué presupuestos la motivación y la conciencia de la ilicitud son exigibles, o mejor, cuándo al sujeto se le puede demandar conducta diversa. Por otro lado, existirán eventos en los cuales a pesar de que el sujeto tenga capacidad de comprensión y conozca la ilicitud del hecho, el Estado no debe exigirle la conducta conforme a derecho, dadas las circunstancias particulares en las que actuó (causales de inculpabilidad).

En todo caso, tal exigibilidad determinará la exclusión o atenuación de la

25 CSJ, Sentencia 26789, 11/03/2009, CSJ Sentencia 32614, 17/08/2011, CSJ 50525, 04/12/2019, y CSJ $53157,05 / 03 / 19$. Sobre este punto es necesario agregar que el rango para la búsqueda de sentencia se realizó entre el año 2000 hasta 2020.

26 CSJ, auto 47781, 25/05/2016, CSJ, auto 47183, 24/02/2016, CSJ, auto 47366, 24/02/2016, CSJ, auto 46027, 09/09/2015, CSJ, auto 45918, 05/82015, auto 44993, 10/06/2015, CSJ, auto 46687, 30/09/2015, CSJ, auto 42075, 10/12/2014, CSJ, auto 42203, 27/08/2014, CSJ, auto 49219, 27/09/2017, CSJ auto 50202 06/12/2017, CSJ auto 53288 25/09/2019, CSJ, auto 51706 05/08/2019 y CSJ auto 54734 26/02/2020.

27 Sentencia 50525, 04/12/2019.

28 Bustos Ramírez, Juan José y Hormazábal, H. Lecciones de Derecho penal, Volumen II. Madrid: Trotta, 1999, pp.33. 
culpabilidad, pero nunca podrá servir de criterio para aumentar la misma. Así las cosas: "Culpabilidad es responsabilidad, pero en una dimensión más profunda que la hasta ahora entendida. Al establecerse su responsabilidad, se plantea la de la sociedad, tanto por el papel que le ha asignado, como por los controles (también los penales y, específicamente, la pena) de todo tipo que le ha impuesto. La conciencia del hombre surge del proceso social, de su relación social. Luego, la sociedad responde también por esa conciencia lograda por el hombre. La conciencia no es primeramente una cuestión psíquica sino histórico-social; es el proceso históricosocial el que determina, en relación a la psiquis del individuo, su conciencia, desarrollo histórico-social y conciencia son inseparables"29.

En su teoría del sujeto responsable ${ }^{30}$, los autores señalan que debe tenerse en cuenta la complejidad del sujeto social y las circunstancias que lo convierten en actor social, dotado de responsabilidad social. El acento no puede ponerse en el criterio de la prevención general, o mejor, en la pura eficacia, dado que convierte al hombre en un mero instrumento de los fines del Estado.

El sujeto responsable lo es debido a la misma sociedad y la relación social concreta de éste y aquella. El hombre cumple un papel asignado por esta, pero es desarrollado por él mismo. Para Bustos, lo que caracteriza al hombre - como actor social en interacción constante con toda la sociedad y demás actores- es que toma conciencia de su papel. "(...) este acto consciente es un acto social, dentro de una relación social. De ahí que sus características físicas, biológicas y psíquicas, haya que considerarlas primeramente en su dimensión social. En esa medida en que el hombre es un actor dentro del proceso social, es que el hombre puede responder de su actuación, por su papel, por lo realizado. Sólo así el hombre tiene capacidad de respuesta. Su capacidad de responder no es de carácter abstracto ni metafísica, sino en razón de la conciencia concreta dentro de una relación social concreta." ${ }^{31}$

Tomando afinidades con su postura, Bustos y Hormazabal dan cuenta de la noción de Muñoz Conde sobre el tema, quien proporciona contenido material al concepto de culpabilidad y la ubica en el ámbito social, más precisamente, adiciona el elemento del rol social del individuo, refiriendo que "la expectativa de un comportamiento está en una relación estrecha con los roles que el individuo asume en la sociedad.

\footnotetext{
29 Ibid., p. 333.

30 Ibid., p. 325.

31 Ibid., p. 333.
} 
Naturalmente el rol concreto tiene que ser precisado en el caso individual"32 Ahora, la culpabilidad como categoría del delito se ha intentado explicar, bien desde el libre albedrío, bien desde el determinismo; siendo ambos planteamientos quiméricos, por cuanto son indemostrables. Su crítica también encuentra asidero en la posición de Roxin, para quien la culpabilidad entraña la capacidad de direccionamiento, pero al no dar cuenta de cómo este puede ser constatable empíricamente, cae de nuevo en la inclusión de un dogma como el libre albedrío.

Bajo esta crítica, Bustos y Hormazabal sostienen que es necesario hacer una revisión de la teoría de la conducta desviada, que en últimas olvida el papel del Estado en la definición de aquello considerado como criminal. Al respecto indicann ${ }^{33}$ :

"Esta teoría de desviación señala, entonces, que todo lo que se aparta de la norma o expectativa de la sociedad surge de por sí, tiene su propia causa. En alguna forma está detrás una cierta concepción totalitaria de la mayoría; lo que dice la mayoría es lo verdadero, lo otro es lo falso, la división clásica entre blanco y negro. (...) Por ello, tiene razón Muñoz Conde cuando señala que "el problema material de la culpabilidad aparece también como un problema político."

En esta medida, tanto la norma como la expectativa surgen de una estructura de poder, encargada de asignar el delito y el delincuente. Por ello consideran que la pregunta del por qué un determinado comportamiento es criminal o desviado, debe estar integrada dentro de un proceso social de asignación.

La libertad del hombre no es el poder obrar de otra manera, ni su determinación por el bien, sino su conciencia dentro de la relación social. Con el finalismo, para Bustos se inicia una apreciación del contenido real de la culpabilidad, sin que lo logrado sea suficiente, como puede entreverse de la aceptación limitada de la exigibilidad de la conducta. Al sujeto aún se le cosifica, no se considera en su integralidad concreta social.

La responsabilidad implica exigibilidad, lo que el Estado puede exigir de una persona frente a una situación concreta. "El Estado no puede exigir si no ha proporcionado o no se dan las condiciones necesarias para que la persona pueda asumir una tarea determinada por lo demás exigida también por el sistema, por ejemplo, el respeto a la norma" ${ }^{\prime 4}$.

Esa responsabilidad se fundamenta a partir de la capacidad de ese individuo para dar respuestas a la satisfacción de sus necesidades en una relación social 
concreta. Cuando ese sujeto da una respuesta desaprobada por el Estado, se castiga. Ahora, lo esencial consiste en resolver qué respuesta determinada puede exigirle el Estado a determinada persona en un caso concreto. Lo anterior significa, en palabras de Bustos y Hormazábal, que:

“El problema no está sólo en relación con el individuo éticamente autónomo que ha de dar una respuesta determinada normativamente frente al conflicto, sino también y antes que nada en el Estado y en lo que éste le puede exigir legítimamente a las personas. No se trata de un juicio a las capacidades de las personas, sino a la capacidad del Estado, en definitiva de su legitimación, para exigir esa respuesta a la persona y para ello el Estado, en los términos del art. 9.2 CE, respecto de ese individuo concreto ha de haber promovido las condiciones para que su libertad e igualdad sea real y efectiva, y removido los obstáculos que impidan o dificulten su plenitud, así como facilitado su participación en la vida política, económica, cultural y social. Por eso, culpabilidad es exigibilidad, o sea, capacidad no de la persona para dar una respuesta determinada, sino capacidad del Estado para exigir esa respuesta." ${ }^{35}$

Así las cosas, la responsabilidad para Bustos se concretiza en la exigibilidad, que a su vez se desglosa en: imputabilidad, exigibilidad de conciencia del injusto y exigibilidad de la conducta. Esa conciencia está dada socialmente, y es este el fundamento de responsabilidad conjunta con la sociedad. Por eso, la reacción social ejercida sobre el injusto deberá tener en cuenta dicha formación de la conciencia del individuo.

\section{Culpabilidad por vulnerabilidad.}

Tomando planteamientos de E. Zaffaroni ${ }^{36}$, La culpabilidad como categoría dogmática del delito consiste en un juicio de reproche jurídico individualizado que vincula al injusto con su autor, y a su vez implica la contención máxima sobre la aplicación del poder punitivo estatal; juicio que deberá incluir el dato de la selectividad y vulnerabilidad del sujeto infractor, pues la falla estructural del poder punitivo no se subsana con la exigencia de autodeterminación del sujeto respecto del hecho cometido. De esta manera, se podrá reducir la irracionalidad del poder punitivo, deber que le asiste a la agencia judicial.

Diferente a la culpabilidad entendida de forma tradicional, la culpabilidad por vulnerabilidad implica tener en cuenta el dato de la selectividad conforme a la

$35 \quad$ Ibid., p. 336

36 Zaffaronı, Eugenio R. Derecho Penal Parte General. Segunda Parte. Teoría del delito. $2^{\text {a }}$ ed. Buenos Aires: Ediar, 2002, p. 654. 
vulnerabilidad del sujeto, por lo que deberá impedir que el poder punitivo supere el reproche que pueda endilgársele al agente, de acuerdo a su esfuerzo personal para alcanzar la situación concreta de vulnerabilidad. Para ello deben tenerse en cuenta los siguientes criterios:

“(a) el vínculo personal del injusto con el autor se establece teniendo en cuenta la forma en que opera la peligrosidad del sistema penal, que puede ser definida como la mayor o menor probabilidad de criminalización secundaria que recae sobre una persona. (b) El grado de peligrosidad del sistema penal para cada persona está dado, en principio, por lo componentes del estado de vulnerabilidad de ésta al sistema penal. (c) El estado de vulnerabilidad se integra con los datos que hacen a su estatus social, clase, pertenencia laboral o profesión, renta, estereotipo que se le aplica, etc., es decir, por su posición dentro de la escala social. (d) No obstante, si bien por lo general la relación entre poder y vulnerabilidad al poder punitivo es inversa, puesto que el poder opera como garantía de cobertura frente al sistema penal, el poder punitivo no se distribuye sólo por el estado de vulnerabilidad, porque si bien todas las personas que comparten un mismo estado de vulnerabilidad padecen pareja frecuencia de riesgos de criminalización, el poder punitivo también selecciona entre ellas a quienes criminaliza"37.

En definitiva, la culpabilidad se traduce en el "reproche del esfuerzo personal por alcanzar la situación concreta de vulnerabilidad al poder punitivo"38, que implica ese descuento de datos selectivos que acercaron al sujeto a la posibilidad de ser seleccionado por el sistema, y únicamente reprochar el aporte del sujeto para aumentar las probabilidades de selección.

\section{El sujeto social como punto de encuentro.}

Esbozados los planteamientos de ambos juristas, tenemos que su notable punto de convergencia radica en la inclusión del estudio de la realidad social de cada individuo, cuyo juicio de exigibilidad se pretende. En otras palabras, para verificar la existencia de responsabilidad penal, deberá analizarse la existencia de una corresponsabilidad social y estata/39, que será evaluada como componente al

37 Ibid., p. 654

38 Ibid., p. 654.

39 Los criterios de aplicación de corresponsabilidad penal al interior del proceso penal serán objeto de desarrollo en obra que será publicada al momento de evaluación de este artículo, titulada “Corresponsabilidad penal como criterio de aplicación del principio de oportunidad en Colombia. 
interior de la misma categoría de culpabilidad.

Ese análisis contextualizado de cada individuo, así como la distribución de cargas sociales y estatales conforme a su competencia, encuentra fuerte fundamento en nuestra Carta Magna, más exactamente en el principio de la dignidad humana. Este principio limita el poder punitivo estatal, que se concreta no solo a través de las penas, sino en la criminalización primaria realizada por el legislador, la persecución selectiva ordenada a los agentes de policía, y la ejecución judicial de las sanciones penales.

Señalan Sotomayor y Tamayo que el fundamento del derecho penal consagrado en el respeto de la dignidad humana (artículo 1 CP), no puede significar que sea este principio la razón para sancionar; "lo que debe interpretarse, más bien, es que el derecho penal encuentra su razón de ser en la limitación de la intervención punitiva estatal, para evitar que en el ejercicio de dicha actividad se desconozcan las exigencias de un trato humano y digno conforme al modelo constitucional." 40

Es así como la corresponsabilidad, antes de ser penal, se enmarca en las cargas prescritas por la constitución política a través de la positivización de principios como la dignidad humana y la igualdad, conforme la adherencia a un Estado constitucional. Dichas cargas se concretan en intervenciones y planes de acción estatales para garantizar condiciones sociales y materiales dignas, conforme a criterios de igualdad material y efectiva; que a su vez permitan una expectativa razonable de convivencia, posteriormente traducida en legitimidad institucional de respuesta punitiva.

Sobre el tratamiento penal digno y diferenciado conforme a las particularidades de cada individuo y la proscripción de la discriminación, Sotomayor y Tamayo señalan ${ }^{41}$ :

“En el campo penal, esta exigencia de diferenciación puede conducir, en consecuencia, a una protección especial de los derechos de individuos en situación de desigualdad material, por una parte, y a unas mayores garantías o unas mayores barreras de contención frente a las pretensiones punitivas del Estado, cuando se trata de juzgar a quien se encuentra en una situación material de desventaja. Esta consideración es la que, por ejemplo, se encuentra en la base de la distinción entre sujetos imputables e inimputables, pues desde tal punto de vista la inimputabilidad no es más que el reconocimiento con carácter general por parte del Estado de que ciertos sujetos, por distintas razones (salud mental, edad o diversidad sociocultural,

Marginalidad: análisis desde la teoría de la culpabilidad por vulnerabilidad".

40 Sotomayor Acosta, Juan Oberto y Tamayo Arboleda, Fernando León. “Dignidad humana y derecho penal: una difícil convergencia. Aproximación al contenido constitucional de la norma rectora del artículo 1 del Código Penal colombiano". En: Revista de Derecho, N 48, 2017, pp. 33.

41 Ibid., p. 39. 
según el artículo 33 del Código Penal), se encuentran en una situación de desigualdad frente a las exigencias del sistema penal".

Este sustento que los autores proponen para el tratamiento diferenciado de la inimputabilidad puede ser trasladado para la atenuante o posible eximente de marginalidad consagrada en el artículo $56 \mathrm{CP}$, pues como se expuso en los planteamiento de la vulnerabilidad por culpabilidad, se predica del individuo una capacidad de autodeterminación disminuida, pero incluso cuando el remanente de exigibilidad es tan poco, ilegitimo resulta su castigo. La desigualdad que entraña la circunstancia de marginalidad es finalmente el sustento de su atenuación o exculpación.

Sobre esta comparación, fíjese que el tratamiento normativo tradicional colombiano entiende la inimputabilidad como un asunto de capacidad de culpabilidad 0 de autodeterminación, aspecto que en cierto grado comparte la atenuante de la marginalidad. Sin embargo, tal abordaje es insuficiente, pues el sustento de ambas subyace en la desigualdad frente a las exigencias del sistema social, que de no considerarse de este modo constituiría un trato discriminatorio, indigno. Esta postura, respecto de la condición de inimputable, es ampliamente abordada por Sotomayor ${ }^{42}$, quien da cuenta de dicha desigualdad social como factor común entre sujetos con condiciones específicas, tales como trastorno mental, inmadurez psicológica, minoría de edad y diversidad sociocultural.

Tal asunto resulta lógico y proporcional, cuando se ejemplifican casos de personas con trastornos o debilidades de diversa índole, participando en desigualdad de condiciones en un sistema capitalista, intentando acceder al mercado laboral, incluso a la oferta educativa, o el más básico ejercicio como ciudadanos con la posibilidad de votar, por ejemplo. Existe pues, un déficit de legitimidad penal en estos casos, que no es ajeno a quienes se encuentran en circunstancias de marginalidad y, por ende, su ámbito de exigibilidad es más reducido.

En esta medida, la noción de la inimputabilidad, como reconocimiento estatal de desigualdad en ciertas personas, así como delimitación de su ámbito de exigibilidad; sirve a su vez de sustento compartido para el tratamiento diferencial en la circunstancia de menor punibilidad analizada. Sobre la situación desigual de un individuo que demanda respuesta distinta del poder punitivo, Sotomayor y Tamayo señalan:

"En definitiva, un derecho penal respetuoso de la exigencia constitucional de

42 Sotomayor Acosta, Juan Oberto. (1996). Inimputabilidad y sistema penal. Editorial: Temis; S.A. Bogotá - Colombia. ISBN: 978-958-35-0115-9., pp. 241-269. 
trato digno está obligado a proteger a todos por igual frente a las injerencias de otras personas, así como frente a las injerencias del propio Estado (...) al mismo tiempo, la exigencia de diferenciación permite, en algunos casos, el recurso a una protección especial o cualificada de los sujetos en posición de desventaja y en otros obliga a no sancionar 0 a hacerlo en menor o distinta medida, cuando el individuo se encuentre en una situación de desigualdad material que así lo amerite, lo cual debería conducir a un coherente desarrollo de eximentes y atenuantes de la responsabilidad penal." ${ }^{43}$

Así las cosas, si bien la culpabilidad entraña la premisa de autodeterminación por parte del autor, la configuración de tal categoría (respecto de sus atenuantes 0 eximentes), vincula factores no necesariamente reafirmantes de dicha falta de autodeterminación, como sería el caso de la vulnerabilidad por selectividad defendida por Zaffaroni. Puede pues predicarse la existencia de autodeterminación, sin que a la vez concurra legitimidad o criterios de justicia y proporcionalidad que permitan una declaratoria de responsabilidad por parte del sujeto activo.

Precisamente, este reconocimiento sobre la diferencia de oportunidades entre sujetos de una misma sociedad, así como los grados o brechas entre su autodeterminación, pone de presente una declaración intrínseca del Estado colombiano, derivado por abstracción del artículo 56 del CP, esto es, la existencia de una corresponsabilidad social.

Se trata pues de trascender la noción de culpabilidad singular respecto del autor del punible, a un concepto que adhiera el componente social al que se circunscribe el agente. Esta consideración de cargas, reconfigura los alcances de la reprochabilidad endilgada al individuo, o mejor, varía la exigencia de actuar de otro modo en un contexto determinado.

Así las cosas, la circunstancia de marginalidad considerada en la disposición jurídica analizada, hace parte del componente de la culpabilidad, que en todo caso podrá tener un grado diferente de incidencia en el arreglo de punición; categoría que implica consideraciones preventivas y de otras finalidades.

Todo lo anterior amerita la necesidad de desarrollar -en posteriores obraslos criterios de aplicación de la corresponsabilidad penal, que a modo de esbozo se contempló como el aporte del Estado y el sujeto activo en la comisión de una conducta punible.

Por lo pronto, en este artículo se orientó sobre la necesidad de ahondar sobre

43 Sotomayor Acosta, Juan Oberto y Tamayo Arboleda, Fernando león. “Dignidad humana y derecho penal: una difícil convergencia. Aproximación al contenido constitucional de la norma rectora del artículo 1 del Código Penal colombiano", cit., p.40. 
estos aspectos, y dinamizar la teoría o hacer de ésta un ejercicio vívido en el proceso penal, optimizando la aplicación de la circunstancia de marginalidad consagrada en el Código Penal colombiano, y ayudando a que su mayor entendimiento sirva al ente acusador y a misma agencia judicial, en sus funciones de racionalizar el ejercicio punitivo, así como de contención al mismo. Restar los niveles de selectividad de nuestro sistema penal, no en pocas veces se traduce en disminuir el clasismo y aporofobia, que pueden encontrar evidencia en la caracterización de la gran parte de población privada de la libertad. En otras palabras, incluir la influencia o el aporte de la marginalidad en la comisión delictiva de un caso específica, materializa un papel contraselectivo del derecho penal, que es en sí, parte de la función judicial.

\section{Conclusiones.}

Colombia, al momento de escribir este artículo, se encuentra en una serie de protestas sociales, inicialmente exacerbadas por el planteamiento de una reforma tributaria que no tendía hacia la reducción de la brecha de clases, pero han venido fundamentándose gradualmente en múltiples causas. Esta situación, aunada al fenómeno de la pandemia, redundará inevitablemente en una agudización a corto plazo de las dificultades locales, pero puede alzarse como una oportunidad para generar cambios de alto impacto económico y social en el panorama nacional.

El derecho penal, desde sus desarrollos teóricos hasta su aplicación práctica, no debe ignorar la realidad en la que se busca su funcionamiento. Es por eso que las categorías dogmáticas del delito no son rígidas, ni pueden serlo. No todo se resuelve o es problema únicamente del asunto probatorio, sino de la lectura que se prevea desde la dogmática, que simplemente atañe al método racional que nos permite comprender el sistema. Los cambios provienen de los datos de realidad que incorporamos a las categorías de análisis.

La culpabilidad responde al porqué es posible señalar a alguien como autor, por lo que debe investigarse cuál es el contenido material de la culpabilidad, siendo necesario partir no del individuo, sino, conforme la tesis de Bustos, del individuo en sociedad. Hombres y mujeres solo pueden ser comprendidos en cuanto viven en sociedad. 
Lo anterior también encuentra un punto de encuentro en los planteamientos de Zaffaroni, que parte de considerar la posición social en que se ubica el sujeto, los estereotipos que le son aplicables, y en todo caso, la probabilidad de ser seleccionados por el sistema penal mediante la criminalización secundaria. Dichos datos conformarán la vulnerabilidad del individuo para ser alcanzado por el poder punitivo.

En consecuencia, el examen y sustento de la circunstancia de marginalidad consagrada en el artículo 56 del Código Penal, como manifestación de la corresponsabilidad penal, implica un análisis teórico y práctico sobre las posibilidades de equilibrar las cargas que han sido desprovistas en proporción justa a un sujeto vulnerable, y cuyo comportamiento le es reprochado.

\section{Bibliografía.}

Asamblea General de las Naciones Unidas. "La extrema pobreza y los derechos humanos", 7 de octubre de 2020. Recuperado de: HTtPS://www.undocs.org/ES/A/75/181/REV.1. Consultado en mayo 26 de 2021.

Bustos Ramírez, Juan José y Hormazábal, Hernán. "Lecciones de Derecho penal", Volumen II. Madrid: Trotta, 1999.

Departamento Administrativo Nacional de Estadística. "Histórico Actualidad DANE 2017", 2017. Recuperado de DANE: https://www.dane.gov.co/index.php/ actualidad-dane/historico-actualidad-dane-2017

Fernández De Soto, Guillermo. "Colombia y el 75 aniversario de las naciones unidas", junio de 2020. Recuperado de https://www.un.org/pga/74/wp-content/ uploads/sites/99/2020/06/Texto-Colombia-y-ONU-75-an\%CC\%83os-junio-182020-final.pdf. Consultado en mayo 26 de 2021.

Oxfam International. "Cinco datos escandalosos sobre la desigualdad extrema global y cómo combatirla". Recuperado de: https://www.oxfam.org/es/cinco-datosescandalosos-sobre-la-desigualdad-extrema-global-y-como-combatirla. Consultado en mayo 26 de 2021.

Oxfam International. "Poder, ganancias y pandemia. De una economía para las élites a una economía para las personas", 2020. Recuperado de: https://www.oxfam. org/es/informes/poder-ganancias-y-pandemia. Consultado en mayo 26 de 2021.

OXfam International. "Desterrados: tierra, poder y desigualdad en América Latina", 
2016. Recuperado de: https://www.oxfam.org/es/informes/desterrados-tierrapoder-y-desigualdad-en-america-latina. Consultado en mayo 26 de 2021.

Oxfam International. "Radiografía de la desigualdad", 2017. Recuperado de: https:// d1tn3vj7xz9fdh.cloudfront.net/s3fs-public/file _ attachments/radiografia de _ la _ desigualdad.pdf. Consultado en mayo 26 de 2021.

Oxfam International. "Premiar el trabajo, no la riqueza", 2018. Recuperado de: https:// d1tn3vj7xz9fdh.cloudfront.net/s3fs-public/file _ attachments/bp-rewardwork-not-wealth-220118-es.pdf. Consultado en mayo 26 de 2021.

Oxfam International. "Combatir la desigualdad en tiempos de coronavirus: Índice de Compromiso con la Reducción de la Desigualdad (CRI) 2020". Recuperado de: https://www.oxfam.org/es/informes/combatir-la-desigualdad-en-tiempos-decoronavirus-indice-de-compromiso-con-la-reduccion-de. Consultado en mayo 26 de 2021.

Organización de las Naciones Unidas. "Colombia rural, razones para la esperanza", 2011. Recuperado de: https://www.undp.org/content/dam/colombia/docs/ DesarrolloHumano/undp-co-ic _ indh2011-parte1-2011.pdf. Consultado en mayo 26 de 2021.

Resultados del índice de desarrollo regional - Latinoamérica (IDERE LATAM). Recuperado de: http://www.iderelatam.com/. Consultado en mayo 26 de 2021. Roxin, Claus. Derecho procesal penal. Buenos Aires: Editores del puerto. 2000.

Ryan, Richard M. y Decl, Edward L. "La Teoría de la Autodeterminación y la Facilitación de la Motivación Intrínseca, el Desarrollo Social, y el Bienestar". En: American Psychologist, Vol. 75, 2000, p. 68-78.

Sierra, Hugo Mario y Cantaro, Alejandro Salvador. Lecciones de Derecho Penal. Parte General. Bahía Blanca: Editorial de la Universidad Nacional del Sur, 2005.

Sotomayor Acosta, Juan Oberto y Tamayo Arboleda, Fernando león. “Dignidad humana y derecho penal: una difícil convergencia. Aproximación al contenido constitucional de la norma rectora del artículo 1 del Código Penal colombiano". En: Revista de Derecho, N0 48, 2017, pp. 21-53.

Sotomayor Acosta, Juan Oberto. Inimputabilidad y sistema penal. Editorial: Temis; S.A. Bogotá - Colombia. ISBN: 978-958-35-0115-9. 1996.

Zaffaroni, Eugenio Raúl y Alagia, Alejandro y Slokar, Alejandro. Derecho Penal Parte General. Segunda Parte. Segunda edición. Buenos Aires, Argentina: Ediar Sociedad anónima editora, comercial, industrial y financiera, 1998, p. 657. 
Zaffaroni, Eugenio Raúl. Manual de derecho penal. Parte general. Buenos Aires: Ediar, 1996.

Zaffaronı, Eugenio Raúl. Derecho Penal Parte General. Segunda Parte. Teoría del delito. $2^{\mathrm{a}}$ ed. Buenos Aires: Ediar, 2002.

\section{Jurisprudencia.}

Corte Constitucional de Colombia, sentencia C-179 de 1994

Corte Constitucional de Colombia, sentencia SU-479 de 2019

Corte Suprema de Justicia de Colombia, Sala de Casación Penal, CSJ, SP, 11 mar 2009, rad. 26789.

Corte Suprema de Justicia de Colombia, Sala de Casación Penal, CSJ, SP, 17 ago 2011, rad. 32614.

Corte Suprema de Justicia de Colombia, Sala de Casación Penal, CSJ, SP, 04 dic 2019, rad. 50525.

Corte Suprema de Justicia de Colombia, Sala de Casación Penal, CSJ, SP, 05 mar 2019, rad. 53157.

Corte Suprema de Justicia de Colombia, Sala de Casación Penal, CSJ, SP, 04 dic 2019, rad. 50525.

Autos

Corte Suprema de Justicia de Colombia, Sala de Casación Penal, CSJ, AP, 10 dic 2014, rad. 42075.

Corte Suprema de Justicia de Colombia, Sala de Casación Penal, CSJ, AP, 27 ago 2014, rad. 42203.

Corte Suprema de Justicia de Colombia, Sala de Casación Penal, CSJ, AP, 09 sep 2015, rad. 46027.

Corte Suprema de Justicia de Colombia, Sala de Casación Penal, CSJ, AP, 05 ago 2015, rad. 45918.

Corte Suprema de Justicia de Colombia, Sala de Casación Penal, CSJ, AP, 10 jun 2015, rad. 44993.

Corte Suprema de Justicia de Colombia, Sala de Casación Penal, CSJ, AP, 30 sep 2015, rad. 46687.

Corte Suprema de Justicia de Colombia, Sala de Casación Penal, CSJ, AP, 25 may 2016, rad. 47781. 
Corte Suprema de Justicia de Colombia, Sala de Casación Penal, CSJ, AP, 24 feb 2016, rad. 47183.

Corte Suprema de Justicia de Colombia, Sala de Casación Penal, CSJ, AP, 24 feb 2016, rad. 47366.

Corte Suprema de Justicia de Colombia, Sala de Casación Penal, CSJ, AP, 27 sep 2017, rad. 49219.

Corte Suprema de Justicia de Colombia, Sala de Casación Penal, CSJ, AP, 06 dic 2017, rad. 50202.

Corte Suprema de Justicia de Colombia, Sala de Casación Penal, CSJ, AP, 25 sep 2019, rad. 53288.

Corte Suprema de Justicia de Colombia, Sala de Casación Penal, CSJ, AP, 05 ago 2019, rad. 51706.

Corte Suprema de Justicia de Colombia, Sala de Casación Penal, CSJ, AP, 26 feb 2020, rad. 54734. 